\title{
STRENGTH ENHANCEMENT FROM HETEROGENEOUS NETWORKS OF ETHYLENE-PROPYLENE/ETHYLENE-PROPYLENE-DIENE
}

\author{
G. S. BuCKLEY, ${ }^{1}$ D. Fragiadakis,${ }^{2}$ C. M. Roland ${ }^{2, *}$ \\ ${ }^{1}$ CAmeron University, DePartment of Physical SCIENCES, LAWton, OK 73505 \\ ${ }^{2}$ NaVAl Research Laboratory, Chemistry Division, CoDE 6120, WASHington, DC 20375-5342
}

RUBBER CHEMISTRY AND TECHNOLOGY, Vol. 84, No. 4, pp. 520-526 (2011)

\begin{abstract}
Random copolymers of ethylene and propylene are usually miscible with the corresponding unsaturated terpolymer (EPDM). Vulcanization of these blends yields networks in which only the EPDM is cross-linked. Despite chemical modification of the EPDM by its reaction with sulfur, there is no phase-separation evident during curing. The blend exhibits substantially higher strength than the corresponding pure EPDM networks, when compared at equal modulus. Thus, nearly miscible blend networks having a large disparity in component cross-linking can circumvent the usual tradeoff between the stiffness and strength of elastomers. This exemplifies a general route to better mechanical properties via blends having a homogeneous phase morphology and whose components have substantially different cross-link densities. [doi: $10.5254 / 1.3601887]$
\end{abstract}

\section{INTRODUCTION}

The mechanical properties of rubbery networks depend primarily on the cross-link density, with the polymer per se having a relatively small effect. The chemical structure of an elastomer affects certain aspects of performance (e.g., chemical and heat resistance, friction, adhesion, gas permeability, biocompatibility, etc.), but the mechanical behavior up through moderate deformations is essentially the same for all flexible-chain polymers. Even the fracture and fatigue properties, in the absence of strain-induced crystallization or mechanically labile cross-links (e.g., "ionomers"1-4), are not especially dependent on the polymer. There are exceptions to this general behavior, usually due to a unique network structure. One example is an interpenetrating polymer network, ${ }^{5}$ which ideally is a cocontinuous, interlocking network of two chemically distinct components. Interpenetration at the segmental level of the two networks is usually not obtained, however, due to phase separation of the thermodynamically immiscible components during crosslinking. Another approach is double network rubbers, in which the same chain segments belong to two networks, formed by cross-linking steps carried out sequentially on the unstrained and the oriented material. Since the properties of an elastomeric network depend on the orientation of the chains, double networks exhibit mechanical behavior distinct from the corresponding single (unoriented) networks. ${ }^{6-8}$

Better mechanical properties have also been achieved with bimodal networks, in which a portion of the chains between cross-links is short, and the remaining network strands are very long. Bimodal networks are prepared by end-linking a large number of low $M w$ precursor chains with a large weight fraction of high $M w$ chains, yielding elastomers with good toughness. ${ }^{9}$ The origin of the improvement is unclear, but has been ascribed to a "delegation of responsibilities," implying that the short network chains enhance the modulus, while long chains provide extensibility. A related method is to blend two polymers, one highly cross-linked and the other lightly or uncross-linked, using a common solvent used to homogenize the mixture. Gong et al. ${ }^{10,11}$ reported remarkable compressive strength for a hydrogel blend of this type. The requirements to achieve exceptional toughness seem to be that the components have very different cross-link densities and the morphology is uniform down to the segmental level. Absent the use of a common solvent (water in the case of hydrogel blends ${ }^{10,11}$ ), the need for 
homogeneity limits this approach, since only a handful of rubbers form thermodynamically miscible blends. ${ }^{12}$ One such pair is 1,4-polyisoprene (e.g., natural rubber) and 1,2-polybutadiene (polyvinylethylene). ${ }^{13,14}$ Differing reactivities for sulfur vulcanization can be exploited to achieve a disparity in network density between the components; however, their chemical modification due to cross-linking tends to induce phase separation. The properties of networks of 1,4-polyisoprene and 1,2-polybutadiene were found to be sensitive to the degree of homogeneity of the phase structure. ${ }^{15}$

In this work we investigate a variation on this approach by mixing two chemically identical polymers, except that one has $1.7 \mathrm{~mol}$. \% unsaturated repeat units. The idea is that the two requirements for improved mechanical properties - phase homogeneity and a disparity in crosslinking density - can be achieved with blends of ethylene-propylene random copolymer (EPR) mixed with ethylene-propylene-diene random terpolymer (EPDM). Ellul and Gent ${ }^{16}$ previously showed this blend to yield enhanced, and strongly rate-dependent, autoadhesion, ascribed to the translational mobility of the unattached EPR chains. Similar results were obtained with butyl rubber networks containing uncross-linkable polyisobutylene. ${ }^{17}$ In the present work we study blends of EPR and EPDM, using sulfur to selectively vulcanize the latter. Such blends are thermodynamically miscible when the difference in weight percent of the ethylene and diene between the two components is less than $12 \%,{ }^{18}$ herein, this difference was $4.3 \%$. We find that the resulting disparity in cross-linking of the components yields better failure properties than that obtained for neat EPDM having the same modulus. This approach offers a means to achieve higher modulus elastomers without sacrificing their strength.

\section{EXPERIMENTAL}

The polymers used herein were DSM Keltan 312 , an EPDM with $4.3 \%$ by weight unsaturation and a Mooney viscosity $(\operatorname{ML}(1+4) 125)=33$, and Keltan 3200A, an EPR with ML(1+4)125 $=51$; both were $49 \%$ ethylene. The formulations are given in Table I (phr refers to the mass per 100 parts of total polymer). All samples were gum rubbers, although a small quantity ( $0.2 \mathrm{phr})$ of carbon black was added to facilitate optical measurements of strain. Mixing was carried out on a Brabender Laboratory Mixer at temperatures in the range from 50 to $65^{\circ} \mathrm{C}$. Curatives were added using a two-roll mill at $\sim 50{ }^{\circ} \mathrm{C}$. Vulcanized test specimens were prepared by compression molding at $150{ }^{\circ} \mathrm{C}$ for $35 \mathrm{~min}$.

TABLE I

RUBBER FORMULATION

\begin{tabular}{lcc}
\hline & Source & \\
\hline Polymer & (DSM) & $100 \mathrm{phr}$ \\
Stearic acid & - & 2 \\
Zinc oxide & - & 5 \\
N660 carbon black & Sterling V (Cabot) & $0.2^{\mathrm{a}}$ \\
Tellurium diethyldithiocarbamate & Ethyl Tellurac (R. T. Vanderbilt) & $0.25-2.3$ \\
Tetramethyl thiuram disulfide & Methyl Tuads (R. T. Vanderbilt) & $0.25-2.3$ \\
2-mercaptobenzothiazole & Captax (R. T. Vanderbilt) & $0.25-2.3$ \\
Dipentamethylene thiuram Hexasulfide & Sulfads (R. T. Vanderbilt) & $0.25-2.3$ \\
Sulfur & (Akrochem) & $0.1-1.4$ \\
\hline
\end{tabular}

${ }^{a}$ To provide better contrast for optical extensometer measurements of strain. 


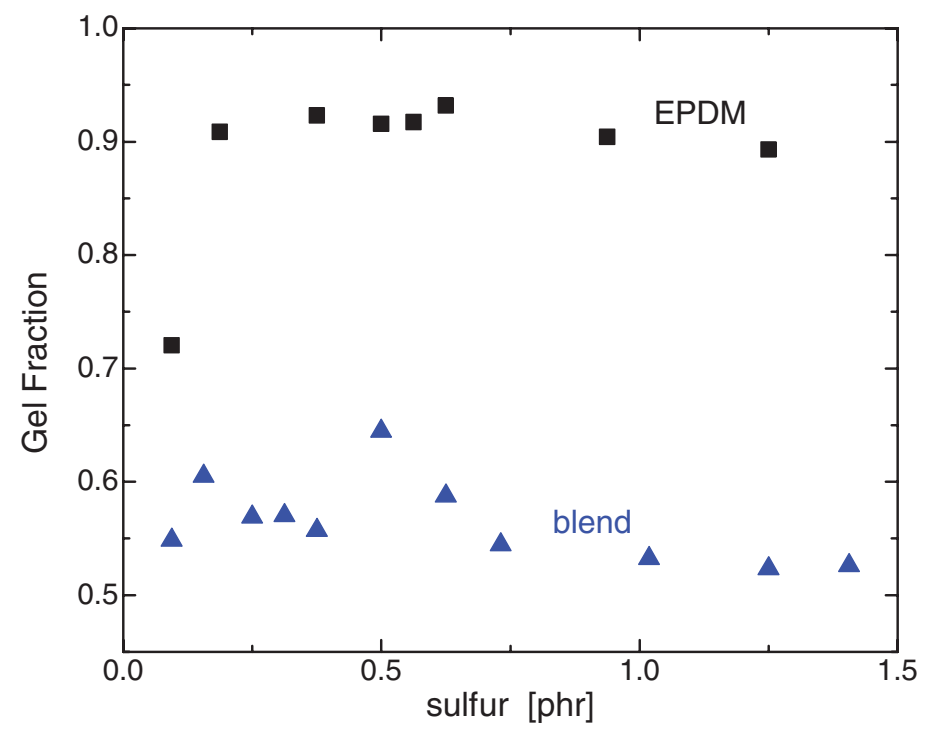

FIG. 1. - Insoluble fraction of network as a function of the sulfur concentration for EPDM (squares) and its blend with EPR (triangles).

Stress-strain measurements were carried out on an Instron 5500R with video extensometer; the nominal strain rate was $0.2 \mathrm{~s}^{-1}$. All data herein are the median of at least five tensile measurements. Samples were Soxhlet extracted over for 9 days using xylene as the solvent, followed by vacuum drying at $25^{\circ} \mathrm{C}$. The dried samples were subsequently swollen in cyclohexane to determine the swelling volume. Transmission electron micrographs employed a JEOL 2000FX operated at $200 \mathrm{kV}$ at the Samuel Roberts Noble Electron Microscopy Laboratory at the University of Oklahoma. Samples were stained in an $\mathrm{OsO}_{4}$ atmosphere for $15 \mathrm{~min}$.

\section{RESULTS}

These particular polymers were chosen in order to prepare a network in which only one component is cross-linked. To verify that this has been achieved, vulcanized samples of the blend were extracted. As seen in Figure 1, the EPR, which comprises $42-46 \%$ of the blend formulation, remains essentially uncross-linked (although it can react via free radicals at higher temperatures); the network is composed mainly of the EPDM. For both materials the cross-linking increases in proportion to the sulfur concentration (Figure 2); network densities shown in Figure 2 were calculated using the Flory-Rhener equation ${ }^{19}$ with a value of 0.35 for the polymer-solvent interaction parameter. ${ }^{20}$ The indicated sulfur concentration for the blend refers to the amount per total polymer, implying equipartition of the curative. The slightly greater polarity of the EPDM and the depletion of free sulfur by the reaction (Le Chatelier's principle) would favor migration of sulfur to this component, assuming any lack of homogeneity of the phase morphology.

The failure properties of elastomers, including tensile strength, fatigue life, and tear resistance, go through a maximum versus the modulus. ${ }^{21,22}$ At very low degrees of cross-linking, a network lacks mechanical integrity, while high levels of cross-links cause embrittlement. This maximum is observed just past the gel point, so that for commercial elastomers, as well as the materials reported on herein, increasing cross-link density leads to lower strength.

Figure 3, which is the main result of this work, shows the tensile strength of the EPDM and its blend with EPR, plotted as a function of the stress at $100 \%$ elongation; the latter is a convenient 


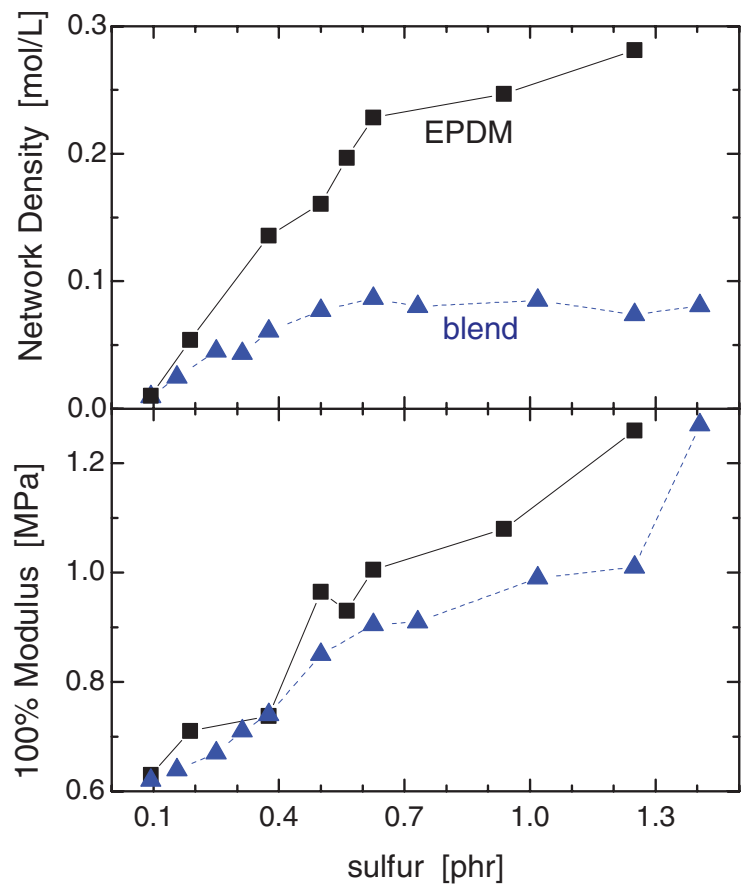

FIG. 2. - (Top) Number density of network chains and (bottom) stress at $100 \%$ tensile strain as a function of sulfur content (divided by 2 for the blend) for EPDM (squares) and the blend (triangles).

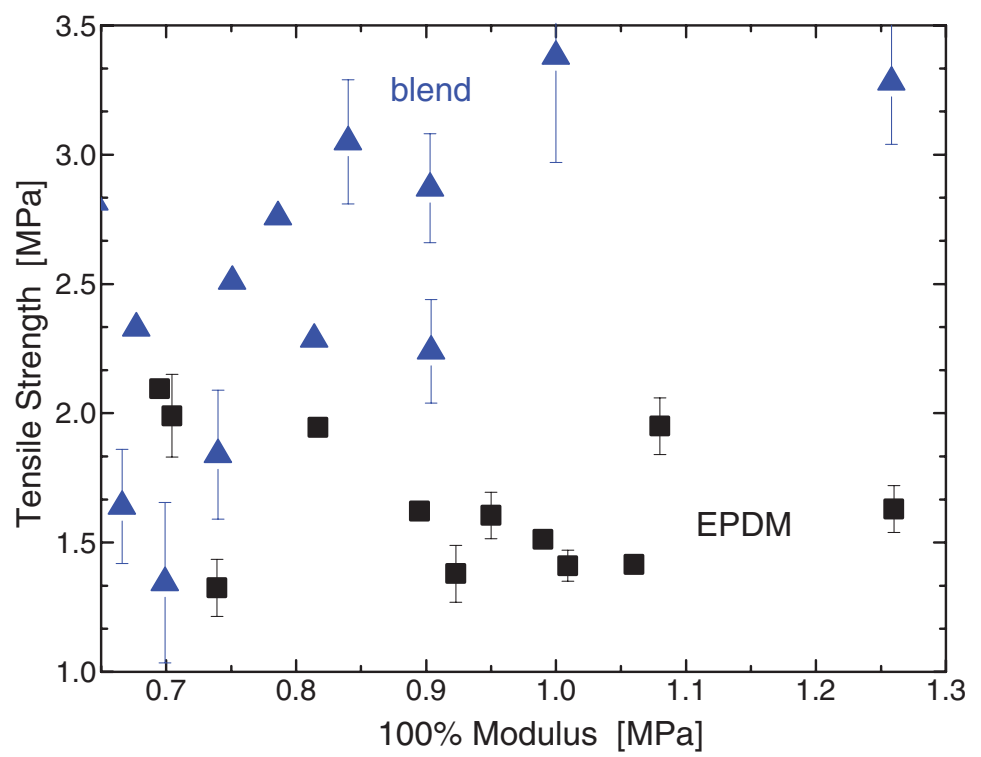

FIG. 3. - Stress at failure vs the stress at $100 \%$ strain for uniaxially stretched samples of neat EPDM (squares) and the $50 / 50$ blend (triangles). 


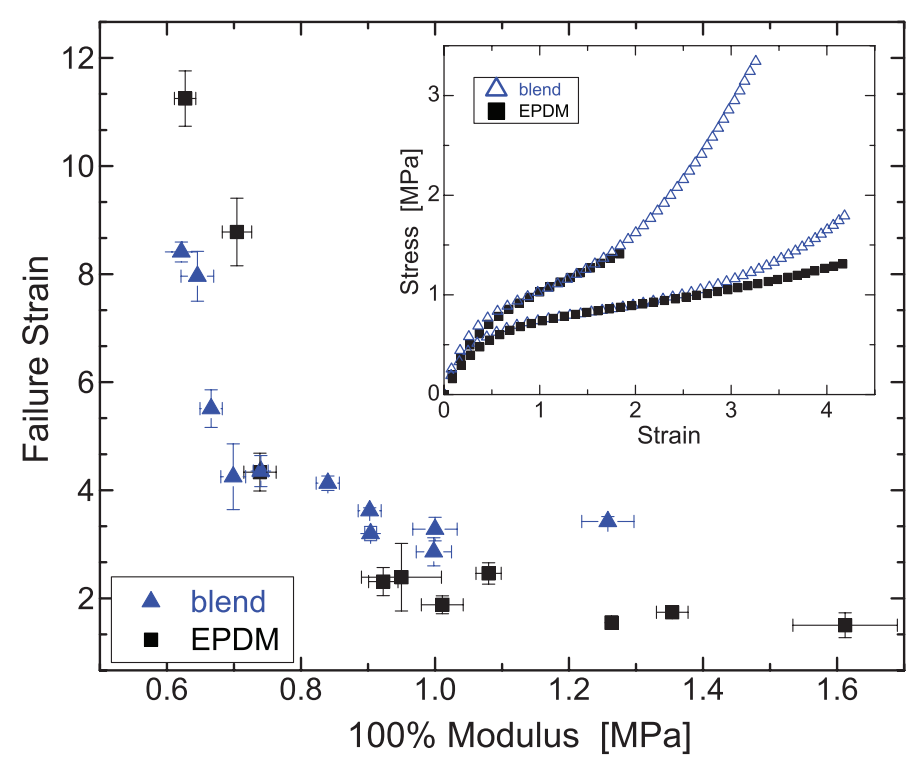

FIG. 4. - Failure strain vs stress at 100\% strain for the neat EPDM (squares) and the blend (triangles). The inset shows that the stress-strain curves are similar, but the blend attains higher extension prior to breaking.

metric of the degree of cross-linking. Note that the relative behavior of the two networks is unaffected by the particular strain used to evaluate the modulus. At constant modulus, the blend has a significantly higher tensile strength than neat EPDM, by as much as twofold. Thus, higher modulus can be achieved in the blend without the usual reduction in strength.

The $100 \%$ modulus for these samples ranged from 0.6 to $1.4 \mathrm{MPa}$. At lower degrees of cross-linking, the failure strains were very high, equal to 10 or more, while the highest stiffness obtainable was limited by the (relatively low) unsaturation of the EPDM component. Except at very low degrees of cross-linking, the failure strain is larger for the blend than for the neat EPDM network (Figure 4). In light of Figure 3, this means that the blends have substantially greater energy to break, by a factor of 4 or more when compared at equal modulus. Representative stress-strain curves for each network type are included in Figure 4.

The approach herein of selectively cross-linking one component of a miscible blend assumes that the homogeneous phase morphology is largely retained after sulfurization. This is not necessarily the case, since the chemical modification of the backbone tends to reduce compatibility. Nevertheless, electron micrographs of the cured blend reveal no phase structure, indicative of a cocontinuous, homogeneous mixture. Although this does not demonstrate thermodynamic miscibility (mixing on the segmental level), any phase-segregation is minimal in the blends. One method to enhance compatibility is through the addition of a common solvent, the method exploited with hydrogels. ${ }^{10,11}$ Toward this end, $20 \mathrm{phr}$ mineral oil was added to both compounds prior to curing. Although this plasticizes the rubbers, reducing their modulus, the tensile strength of the blend remains as much as 50\% higher than that of the EPDM, when compared at equal modulus. This result is consistent with negligible phase-separation in the absence of a compatibilizing solvent.

\section{CONCLUSIONS}

Mechanical properties, specifically the failure properties, of EPDM are improved by the incorporation of saturated and thus nonvulcanizable EPR. For samples compared at equal modulus, 
the tensile strength and the strain-to-break are substantially greater in the blend compared to the neat EPDM. Since these elastomers are not reinforced with filler, they are relatively weak, as expected for gum rubbers; nevertheless, the disparity in cross-linking of the blend components allows a better trade-off between stiffness and strength. Similar behavior was seen in butyl rubber networks containing unattached polyisobutylene chains, for which Hamed and Ogbimi ${ }^{23,24}$ observed higher tear strengths. The greater strength herein is also analogous to the improvements obtained with bimodal networks 9 and other systems with mixed components of significantly different cross-link densities. ${ }^{10,11}$

Our interpretation of the origin of the observed strength enhancement is only speculative; various related mechanisms may be operative. While the EPDM network confers high elasticity, the unattached EPR chains can alleviate stress concentrations through local rearrangements and flow. The inference is greater dissipation at the crack tip. This is the idea conveyed by the term "delegation of responsibilities" used to describe bimodal networks. ${ }^{9}$ The mobility of the free chains may also cause a reduction in the inherent flaw size of the material, which would lead directly to improved failure properties. ${ }^{21,25}$

\section{ACKNOWLEDGEMENTS}

The work was supported by the Office of Naval Research (Ships and Engineering Systems Division, Code 331). G.S.B. acknowledges an American Association of Engineering Education fellowship and funding from the Francis Jo Richardson Lectureship at Cameron University. D.F. acknowledges a National Research Council postdoctoral fellowship. The authors thank Greg Strout (University of Oklahoma) for the transmission electron microscopy. Annie Ellis, Matthew Thompson, and Jai Pathak contributed to early aspects of this work.

\section{REFERENCES}

${ }^{1}$ W. J. MacKnight and R. D. Lundberg, RubBer CHEM. TeChnOL. 57, 652 (1984).

${ }^{2}$ P. Antony and S. K. De, J. Macromol. Sci., Polym. Rev. C41, 41 (2001).

${ }^{3}$ I. S. Choi, C. M. Roland, and L. C. Bissonnette, RubBer CHEM. TECHNOL. 67, 892 (1994).

${ }^{4}$ G. R. Hamed and K. T. Han, RubBer Chem. TeChNOL. 63, 806 (1990).

5“Advances in Interpenetrating Polymer Networks,” D. Klempner and K. C. Frisch, Eds., Technomic, Lancaster, 1989, Vol. 1.

${ }^{6}$ R. D. Andrews, A. V. Tobolsky, and E. E. Hanson, J. Appl. Phys. 17, 352 (1946); A. Greene, K. J. Smith, and A. Ciferri, Trans. Faraday Soc. 61, 2772 (1965).

${ }^{7}$ P. G. Santangelo and C. M. Roland, RubBer CHEM. TeCHNOL. 67, 359 (1994); 68, 124 (1995).

${ }^{8}$ P. H. Mott and C. M. Roland, Macromolecules 33, 4132 (2000).

${ }^{9}$ J. E. Mark, Macromol. Symp. 191, 121 (2003); RubBer CHEM. TECHNOL. 72, 465 (1999).

${ }^{10}$ J. P. Gong and Y. Katsuyama, Adv. Mater. 15, 1155 (2003).

${ }^{11}$ J. P. Gong, Soft Matter 6, 2583 (2010).

${ }^{12}$ C. M. Roland, RubBer CHEM. TECHNOL. 62, 456 (1989).

${ }^{13}$ C. M. Roland, Macromolecules 20, 2557 (1987).

${ }^{14}$ D. W. Tomlin and C. M. Roland, Macromolecules 25, 2994 (1992).

${ }^{15}$ J. Wang and C. M. Roland, Polymer 46, 4160 (2005).

${ }^{16}$ M. D. Ellul and A. N. Gent, J. Polym. Sci., Polym. Phys. Ed. 23, 1823 (1985).

${ }^{17}$ M. D. Ellul and A. N. Gent, J. Polym. Sci., Polym. Phys. Ed. 23, 1953 (1984).

${ }^{18}$ H. G. Dikland and V. Van Duin, RubBer CHEM. TECHNOL. 76, 495 (2003).

${ }^{19}$ P. J. Flory and J. Rehner, J. Chem. Phys. 11, 521 (1943). 
20 “Polymer Handbook,” J. Brandup, E. H. Immergut, and E. A. Grulke, Eds., (Wiley, New York, 1999).

${ }^{21}$ G. R. Hamed, RubBer CHEM. TECHNOL. 56, 244 (1983).

${ }^{22}$ C. M. Roland, "Viscoelastic Behavior of Rubbery Materials," (Oxford University Press, New York, 2011).

${ }^{23}$ G. R. Hamed and F. Ogbimi, RubBer ChEM. TeChnOL. 56, 1111 (1983).

${ }^{24}$ G. R. Hamed and F. Ogbimi, RuBBER CHEM. TECHNOL. 59, 347 (1986).

${ }^{25}$ I. S. Choi and C. M. Roland, RuBber CHEM. TECHNOL. 69, 591 (1996).

[ Received January 2011, Revised May 2011] 